\title{
Dinâmica da água nas palhadas de milho, milheto e soja utilizadas em plantio direto
}

\author{
Fernando Antônio Macena da Silva( ${ }^{(1)}$, Hilton Silveira Pinto ${ }^{(2)}$, Eric Scopel ${ }^{(3)}$, Marc Corbeels $^{(3)}$ e François Affholder $^{(4)}$ \\ (1)Embrapa Cerrados, Caixa Postal 08223, CEP 73310-970 Brasília, DF. E-mail: macena@cpac.embrapa.br (2)Universidade Estadual de Cam- \\ pinas, Cidade Universitária Zeferino Vaz, Barão Geraldo, CEP 13083-970 Campinas, SP. E-mail: hilton@cpa.unicamp.br (3)Embrapa Cerrados/ \\ Centre de Coopération Internationale en Recherche Agronomique pour le Développement (CIRAD), Caixa Postal 08223, CEP $73310-970$ \\ Brasília, DF. E-mail: eric.scopel@cirad.fr, marc.corbeels@cirad.fr ${ }^{(4)}$ CIRAD, Ambassade de France, 57, Tran Hung Dao, Hanoi, Vietnam. \\ E-mail: francois.affholder@cirad.fr
}

\begin{abstract}
Resumo - O objetivo deste trabalho foi avaliar o efeito das palhadas de milho, milheto e soja na capacidade de interceptação e de armazenamento de água, velocidade de dessecamento, porcentagem de cobertura do solo, interceptação da radiação solar e escoamento superficial, assim como incorporar estes efeitos em um modelo de crescimento de plantas. As palhadas de milheto e de milho apresentaram capacidade maior de armazenar água do que a de soja: 3,26, 3,24 e 2,62 g de água por grama de palhada, respectivamente. A quantidade de água perdida pelos resíduos foi proporcional à evapotranspiração potencial. As taxas de cobertura foram equivalentes nos três tipos de material. Os três tipos de palhada foram similares na interceptação das radiações fotossinteticamente ativa e infravermelha. Os resíduos do milheto foram eficientes no controle do escoamento superficial: do total de $843,5 \mathrm{~mm}$ de água precipitada, apenas $45,5 \mathrm{~mm}$ foram perdidos pelo escoamento superficial no sistema de plantio direto enquanto no convencional as perdas de água foram de 222,5 mm. Os modelos linear e exponencial expressam de forma significativa a maior parte das relações estudadas.
\end{abstract}

Termos para indexação: fluxos hídricos, balanço hídrico, modelagem, Cerrado.

\section{Water fluxes in maize, millet and soybean plant-residue mulches used in direct seeding}

\begin{abstract}
The objective of this work was to evaluate the effects of crop residue mulches from maize, millet and soybean on water storage capacity, water evaporation, soil cover, solar radiation interception and surface water run-off as well as to incorporate these effects in a crop growth model. The mulch of millet and maize presented higher capacity for water storage than soybean mulch: 3.26, 3.24 and $2.62 \mathrm{~g}$ of water per gram of dry matter, respectively. Water losses from wet mulches were related to the potential evapotranspiration. The soil cover levels were similar among the three types of material. The three types of mulch intercepted similar quantities of photosynthetically active radiation and infrared radiation. The mulch of maize straw was slightly more efficient in intercepting radiation than that from millet or soybean. Mulching with millet residues was efficient in the control of surface water run-off: only $45.5 \mathrm{~mm}$ of water (out of $843.5 \mathrm{~mm}$ rainfall) was lost through runoff under the no-till system with millet as cover crop, whereas $222.5 \mathrm{~mm}$ of water was lost in the conventional system with tillage. Most of the relations derived in this work could be described by exponential models.
\end{abstract}

Index terms: water flow, water balance, modeling, Savanna.

\section{Introdução}

A compactação e a erosão dos solos do Cerrado são os principais problemas ambientais causados pela utilização intensa de implementos agrícolas, associada ao monocultivo da soja e do milho e ao uso excessivo de agroquímicos (Resck, 1998). Uma das tecnologias mais utilizadas pelos produtores, capaz de diminuir os proble- mas de degradação dos recursos naturais, é o sistema plantio direto. Essa técnica tem como premissa o nãorevolvimento do solo e a diversificação de espécies, com rotação de culturas, e a manutenção dos resíduos vegetais na superfície do solo (Denardin \& Kochhann, 1993).

A palhada, presente na superfície do solo, representa a essência do plantio direto e provoca modificações, no ambiente do solo, que afetam o balanço hídrico das cultu- 
ras; também reduz o impacto das gotas de chuvas, protegendo o solo contra a compactação, diminuindo o escoamento superficial, e aumentando o tempo e a capacidade de infiltração da água (Derpsch, 1977; Scopel, 1994; Lal, 1998; Saturnino, 2001). Funciona como uma camada dissipadora da radiação solar que chega ao solo, reduzindo a evaporação da água (Ritchie \& Burnett, 1971; Idso et al., 1974; Novak et al., 2000) e também a amplitude hídrica e térmica do solo (Unger \& Parcker, 1976; Arreola Tostado, 1996; Scopel et al., 1999). Possibilita condições melhores de conservação de umidade para o crescimento e o desenvolvimento das culturas, minimizando efeitos adversos decorrentes da falta de chuva (Sidiras et al., 1983; Derpsch et al., 1990; Salton et al., 1998; Silva, 2004).

Um instrumento de grande potencial que integra os componentes do balanço hídrico com respostas das culturas ao ambiente são os modelos de simulação de crescimento e de produção das culturas. Esses modelos têm uma função importante na avaliação do risco climático, na determinação do índice de estresse hídrico e na estimativa dos rendimentos.

Nos últimos 20 anos, houve aumento considerável da utilização de modelagem em ciência agrícola, com a finalidade de simular processos no sistema solo-plantaatmosfera. Atualmente, já existem modelos que consideram os efeitos das palhadas no balanço hídrico e na simulação dos rendimentos das plantas (Arreola Tostado, 2000). Porém, ainda não existe um modelo que avalie as modificações impostas ao balanço hídrico das culturas, no sistema de plantio direto, nas condições edafoclimáticas do Cerrado brasileiro, uma vez que esses modelos não consideram os efeitos da palhada.

O objetivo deste trabalho foi avaliar o efeito dos resíduos de milho, milheto e soja que permanecem no solo, no sistema plantio direto, sobre porcentagem de cobertura do solo, interceptação da radiação solar, capacidade de interceptação e armazenamento de água, velocidade de secagem e escoamento superficial, assim como incorporar esses efeitos em um modelo de crescimento de plantas.

\section{Material e Métodos}

O trabalho foi conduzido no campo experimental da Embrapa Cerrados, em Planaltina, DF, a uma altitude de $1.175 \mathrm{~m}, 15^{\circ} 35^{\prime} 30^{\prime \prime} \mathrm{S}$ e $47^{\circ} 42^{\prime} 0^{\prime \prime} \mathrm{O}$.
O clima é do tipo tropical estacional (Aw), conforme classificação de Köppen, com precipitação média anual de $1.400 \mathrm{~mm}$, concentrada de outubro a março. O período seco, definido em termos de deficit hídrico, é de cinco a seis meses (abril a setembro), e as médias anuais das temperaturas máxima e mínima são de 26,4 e $15,9^{\circ} \mathrm{C}$, respectivamente.

Os dados climáticos foram medidos na estação meteorológica Campbell, próxima ao local onde foi conduzido o experimento. Esses dados incluíram precipitação diária (mm), radiação solar (cal cm² por dia), velocidade média diária do vento $\left(\mathrm{m} \mathrm{s}^{-1}\right)$, temperatura do ar máxima e mínima $\left({ }^{\circ} \mathrm{C}\right)$ e umidade relativa do ar (\%). A evapotranspiração potencial (mm por dia) foi estimada pelo método tradicional de Penman.

A relação entre a quantidade de palha e a cobertura do solo foi estabelecida por meio de um dispositivo experimental, fabricado no Laboratório de Biofísica Ambiental da Embrapa Cerrados, com o qual se delimitou uma área de $1 \mathrm{~m}^{2}$ e, a uma distância fixa do solo, instalou-se uma máquina digital para fotografar as diferentes quantidades de palhada do milho, do milheto e da soja, distribuídas aleatoriamente $(0,5,1,0,1,5,2,0,2,5$, 3,0, 3,5, 4,0, 4,5, 5,0, 6,0, 8,0, 9,0, 10,0, 11,0 tha-1).

Com o software ENVI 4.0, realizou-se uma classificação supervisionada pelo método da máxima verossimilhança, considerando-se apenas duas classes em cada foto: palhada (solo coberto); e solo descoberto. Os valores porcentuais de cada classe foram estimados pelo módulo estatístico presente no ENVI.

Para medir a interceptação das radiações fotossinteticamente ativa (RFA) e infravermelha (RIV) pela palhada, realizou-se um experimento composto de uma placa de vidro com dimensões de 50x150 cm (área de $0,75 \mathrm{~m}^{2}$ ), no qual foram distribuídas, aleatoriamente, diferentes quantidades de palhada. Com o aparelho (Pickhélios) provido de sensores para registrar simultaneamente a radiação solar acima e abaixo da placa de vidro, foram medidas as radiações interceptadas pela palhada e as que chegaram à superfície do solo.

Para se obter a porcentagem de RFA e RIV interceptadas pela placa de vidro, efetuou-se uma correção, na qual foi usada a seguinte fórmula:

$\mathrm{RIA}=\left[\left(\operatorname{RAM}-\left(\frac{100-\mathrm{TC}}{100}\right)\right) \mathrm{RIV}\right]$

em que RIA é a radiação interceptada ajustada (\%); RAM é a radiação interceptada medida pelo Pickhélios (\%); TC é a taxa de cobertura da palhada, 
estimada no item relação entre quantidade de palha e cobertura do solo; RIV é a radiação interceptada pela placa de vidro (\%).

A estimativa da capacidade de armazenamento de água das palhadas foi feita por meio de um experimento em que foram colhidas amostras representativas das palhadas de milho (folhas, colmos e sabugos) e soja (folhas, colmos e vagens). Já a palhada do milheto foi cortada rente ao solo com as folhas, os colmos e as panículas. A capacidade máxima de armazenamento da água foi estimada da seguinte maneira: diferentes quantidades de cada tipo de palhada foram depositadas, durante 12 horas, num recipiente com água para completo encharcamento; as amostras foram retiradas da água e permaneceram por duas horas num ambiente de sombra total para que o excesso fosse drenado completamente (água gravitacional). As amostras úmidas foram pesadas $\left(\mathrm{P}_{\mathrm{um}}, \mathrm{g}\right)$ e levadas para a estufa a $70^{\circ} \mathrm{C}$, durante 72 horas; em seguida, as amostras secadas na estufa foram pesadas $\left(\mathrm{P}_{\mathrm{sec}}, \mathrm{g}\right)$. A capacidade porcentual de armazenamento (CA, \%) da palhada, foi determinada pela fórmula:

$\mathrm{CA}=\frac{\left(\mathrm{P}_{\mathrm{um}}-\mathrm{P}_{\mathrm{sec}}\right)}{\mathrm{P}_{\mathrm{sec}}} 100$

Depois de calculada a CA, foi possível estimar a lâmina máxima (LM, mm) que a palhada pode armazenar, em relação à sua quantidade de matéria seca por hectare $\left(\mathrm{Q}, \mathrm{t} \mathrm{ha}^{-1}\right)$ :

$\mathrm{LM}=\frac{\mathrm{CA} \mathrm{Q}}{1000}$

No estudo da dinâmica de secagem das palhadas de milho, milheto e soja foram consideradas 1, 4, 8, 12 e $16 \mathrm{t} \mathrm{ha}^{-1}$ de resíduos de milho e 1, 3, 6, 9 e $12 \mathrm{t} \mathrm{ha}^{-1}$ dos resíduos de milheto e soja. Utilizaram-se valores mais elevados para o milho, em virtude de essa cultura produzir maior quantidade de biomassa que as anteriores.

Em cada caso, a perda de água pela palhada foi relacionada com a quantidade de energia recebida e sua determinação seguiu as seguintes etapas: amostras das palhadas foram previamente encharcadas durante 12 horas; repartidas em quatro subamostras para cada tipo e quantidade, e distribuídas em quatro peneiras de $0,25 \mathrm{~m}^{2}$ de área $(50 \times 50 \mathrm{~cm})$, as quais foram colocadas sobre a superfície do solo descoberto, previamente molhado, até alcançar sua capacidade de campo; as peneiras foram pesadas a cada hora, durante o dia, em balança com precisão centesimal; calculou-se a umidade inicial (\%), a cada hora de medição, pela seguinte fórmula:

$\mathrm{U}=\frac{\left(\mathrm{P}_{\mathrm{um}}-\mathrm{P}_{\mathrm{sec}}\right)}{\mathrm{P}_{\mathrm{sec}}} 100$

em que $\mathrm{P}_{\mathrm{um}}$ é o peso da palhada úmida (g); $\mathrm{P}_{\text {sec }}$ é o peso da palhada secada em estufa (g) a $70^{\circ} \mathrm{C}$ por 72 horas. A evapotranspiração de referência foi calculada pelo método de Penman (ETPPenman) para o dia da realização das pesagens; admitindo que a secagem dos resíduos é decorrente da demanda evaporativa, e que essa demanda horária está ligada à quantidade de radiação

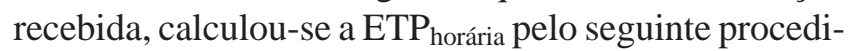
mento:

$\mathrm{ETP}_{\text {horária }}=\mathrm{ETP}_{\text {dia }} \frac{\operatorname{Rg}_{\text {horária }}}{\operatorname{Rg}_{\text {dia }}}$

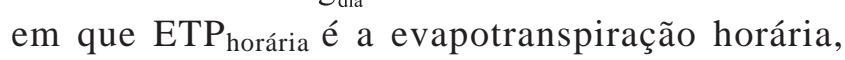
corrigida em relação à radiação (mm por hora); ETP $_{\text {dia }}$ é a evapotranspiração de referência do dia (mm por dia); Rghorária é a radiação global em cada hora das medições ( $\mathrm{J} \mathrm{cm}^{-2}$ por hora); $\mathrm{Rg}_{\text {dia }}$ é a radiação global no dia das medições ( $\mathrm{J} \mathrm{cm}^{-2}$ por dia). Em seguida, calculou-se a evaporação potencial da palhada de acordo com a radiação por ela recebida ( $\left.\mathrm{EV}_{\text {palhada }}\right)$, segundo Arreola Tostado (1996):

$\mathrm{EV}_{\text {palhada }}=\operatorname{ETP}_{\text {horária }}\left(1-\mathrm{e}^{-\beta \mathrm{Q}}\right)$

em que $\beta$ é o coeficiente de ajuste entre quantidade de palha e porcentagem de radiação interceptada (calculado no item interceptação da radiação solar pela palhada) e $\mathrm{Q}$ é a quantidade de palha, $\mathrm{t} \mathrm{ha}^{-1}$. Finalmente, calculou-se a evapotranspiração potencial acumulada durante o experimento ( $\mathrm{EV}_{\text {palhada }}$ acumulada):

$\mathrm{EV}_{\text {palhada }}$ acumulada $=\sum_{1}^{\mathrm{h}} \mathrm{EV}_{\text {palhada }}$

em que h é o número de horas.

As medições foram feitas em $16 / 9 / 2002$, nos resíduos de milheto, 22/9/2002 nos de milho e 23/9/2002 nos de soja.

A fim de medir o escoamento superficial, foi utilizado um dispositivo experimental instalado em um Latossolo Vermelho-Amarelo distrófico, textura argilosa, no Campus II da Universidade Federal de Goiás, Escola de Agronomia.

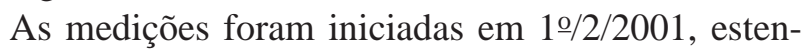
dendo-se até 11/3/2002, sendo feito o acompanhamento em duas parcelas: uma representativa do sistema de manejo convencional (gradagem do solo); a outra, do 
sistema de plantio direto, com o milho em sucessão ao milheto. No início das medições, existiam no solo $4 \mathrm{t} \mathrm{ha}^{-1}$ de biomassa de milheto, que foi se decompondo ao longo do período experimental.

O escoamento superficial foi quantificado para cada evento pluvial, com base no trabalho realizado por Scopel et al. (1999), que preconizaram o uso de parcelas com dimensões de $10 \mathrm{~m}$ de comprimento por $2 \mathrm{~m}$ de largura, totalizando $20 \mathrm{~m}^{2}$ de área e com $4 \%$ de declividade. Essas parcelas foram delimitadas por paredes metálicas enterradas no chão e munidas com sistemas coletores de enxurrada, na extremidade mais baixa. As perdas de água foram avaliadas diariamente, depois das chuvas, nos tanques coletores, por meio de leituras da altura da água depositada neles.

\section{Resultados e Discussão}

As relações ajustadas entre solo descoberto e quantidade de palha de milho, milheto e soja são apresentadas na Figura 1. Esses ajustes podem ser usados como modelos para estimativa da taxa de cobertura do solo (TC, \%) decorrente da quantidade de resíduos. Os valores dos coeficientes de determinação resultantes do ajuste foram superiores a 0,94 .

Para 3,5 t ha ${ }^{-1}$ de resíduo de soja, 35\% da superfície do solo ficam desprotegidos, enquanto as mesmas quantidades de resíduos de milheto e de milho oferecem proteção mais eficiente, pois, respectivamente, 25 e $20 \%$ do solo ficam descobertos (Figura 1).

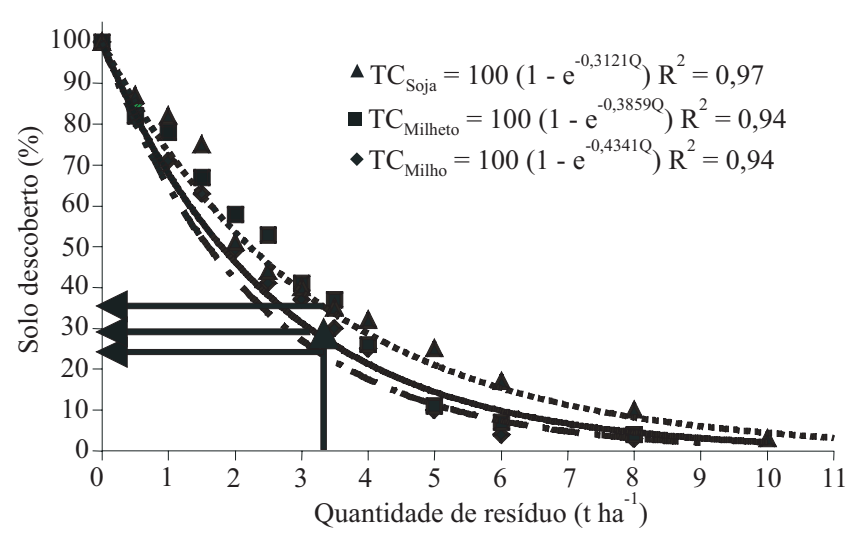

Figura 1. Modelos gerados de taxa de cobertura do solo (TC, \%), a partir do ajuste exponencial entre porcentagem de solo descoberto e quantidade de resíduos de palha de milho (-..), milheto (-) e soja (....).
Os maiores valores dos coeficientes ajustados $(\alpha)$ foram encontrados para o milho e o milheto $(0,4341 \mathrm{e}$ 0,3859 , respectivamente). Isso significa que essas culturas, além da vantagem de produzir grande quantidade de resíduo (8 a 9 t ha-1$^{-1}$ ), vão cobrir totalmente o solo, segundo o modelo gerado e, dessa forma, contribuirão para reduzir não só perdas de água como também perdas de solo. A contribuição de soja foi menor, pois, raramente, a biomassa deixada na superfície ultrapassa 2,5 t ha ${ }^{-1}$ de matéria seca (Ruedell, 1998), cobrindo entre 50 e $55 \%$ da superfície do solo.

As equações apresentadas na Figura 1 estimam eficientemente a taxa de cobertura do solo de acordo com os três tipos de palhada estudados. Essas equações foram incorporadas, por Scopel et al. (2004), a um modelo de simulação do balanço hídrico da cultura do milho em sistema de plantio direto.

Os diferentes tipos de palhada atuam de maneira similar, tanto com a RFA como com a RIV. Com base nos dados obtidos, estabeleceu-se um ajuste, do tipo exponencial, entre os valores porcentuais das RFA e RIV que atingiram o solo, e as quantidades de palha de milho, milheto e soja.

Assim como em Novak et al. (2000), verifica-se ajuste entre a quantidade de palha e os porcentuais da RFA que chegam ao solo (Figura 2). Resultados semelhantes foram encontrados para a RIV. Os coeficientes de determinação foram superiores a 0,87 em todas as relações estudadas.

Verifica-se que os três tipos de palhada apresentam comportamentos similares, porém, a do milho, da mesma forma que se observou em relação à taxa de cobertura do solo, foi ligeiramente mais eficiente na interceptação das quantidades de radiação $(\beta=0,2403)$ (Figura 2).

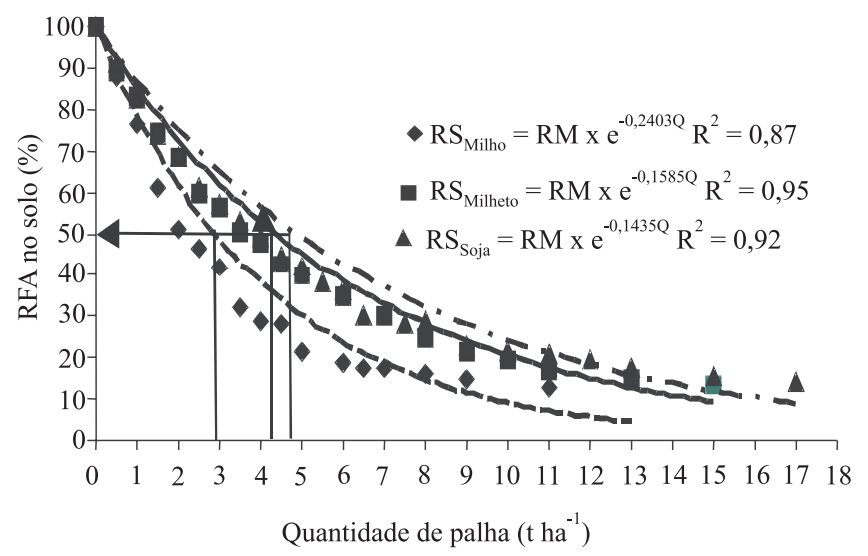

Figura 2. Modelos gerados de interceptação da radiação solar (RS, $\mathrm{W} \mathrm{m}^{-2}$ ) a partir do ajuste exponencial entre porcentagem da RFA que chega ao solo e a quantidade de palha de milho (...), milheto (-) e soja (---). 
De acordo com os valores simulados, quando se aplicam 4 t ha $^{-1}$ da palhada do milho, apenas $35 \%$ da radiação chega ao solo, ao passo que com essa mesma quantidade de resíduos de milheto ou de soja, 55 e 58\%, respectivamente, da radiação atingem o solo.

Os modelos encontrados para estimativa da radiação que chega ao solo (Figura 2) são subsídios importantes, incorporados por Scopel et al. (2004) nas funções de balanço hídrico, que consideram a radiação solar como a principal fonte de energia que participa do processo de evaporação do solo.

As palhadas de milheto e de milho apresentaram capacidade maior para armazenar água do que a da soja: 3,26, 3,24 e 2,62 g de água por g de palhada, respectivamente. Esses resultados confirmam os valores encontrados por Scopel et al. (1999). A maior capacidade dessas palhadas armazenarem água, provavelmente, deve-se à estrutura porosa do seu material constituinte, como o colmo e a panícula, enquanto a soja apresenta material mais fino e mais fibroso.

A análise estatística, realizada para ajustar dados observados a uma regressão linear simples, mostra que a quantidade máxima de armazenamento da água (Y, mm) dos três tratamentos correlaciona-se significativamente com a quantidade da palhada. Isto demonstra que a capacidade de armazenamento é diretamente proporcional à soma da capacidade de armazenamento de cada elemento constituinte da palhada, e que não há armazenamento entre os elementos. Os valores da constante a e os respectivos modelos resultantes dos ajustes estão na Figura 3. As análises apresentaram coeficientes de determinação superiores a 0,98 .

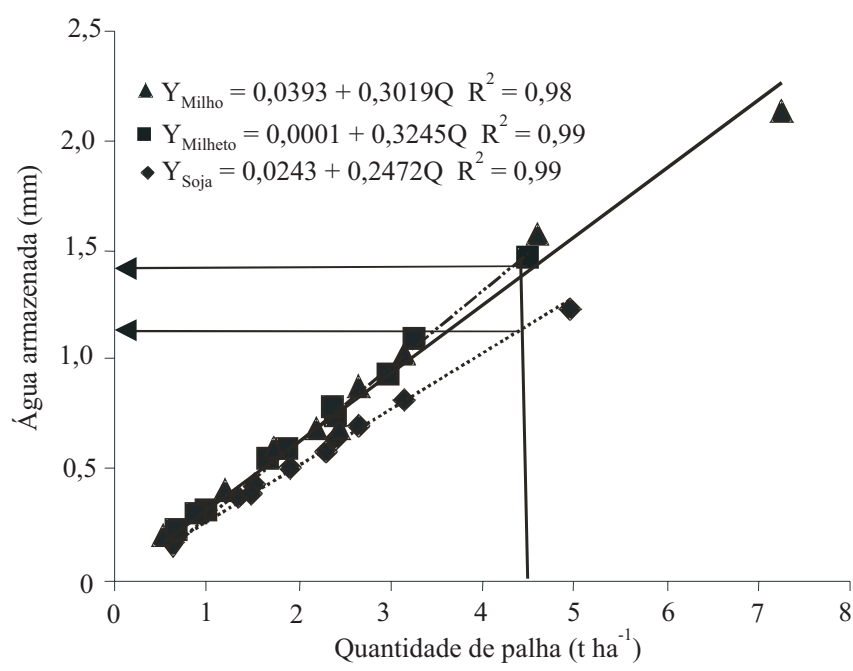

Figura 3. Ajuste da capacidade de armazenamento da água (mm) de acordo com a quantidade da palhada de soja (-..-), milheto (---) e milho $(-)$ e os respectivos modelos gerados.
Na Figura 3, pode-se constatar a capacidade de armazenamento da água dos três tipos de palhada. Considerando-se uma quantidade de resíduo de $4,5 \mathrm{t} \mathrm{ha}^{-1}$, como indicado pelas setas na figura, os restos de cultura do milho e do milheto apresentaram capacidade para interceptar e armazenar apenas 1,45 mm de água por $\mathrm{m}^{2}$ ou 14,5 $\mathrm{m}^{3}$ de água por ha, ao passo que os da soja só conseguiram armazenar $1,18 \mathrm{~mm}$, equivalente a 11,8 $\mathrm{m}^{3} \mathrm{ha}^{-1}$. Estes valores estão muito próximos dos encontrados por Arreola Tostado (1996), que comprovou que 4,5 $\mathrm{t} \mathrm{ha}^{-1}$ de palha de milho foi capaz de armazenar 1,7 mm de água e, por Savabi \& Stott (1994), que encontraram valores de 1,4 $\mathrm{mm}$ de água armazenada no mesmo tipo de palhada.

Se, por um lado, a palhada apresenta vantagens por funcionar como uma camada dissipadora de energia cinética das gotas de chuva, diminuindo as perdas por erosão e, também, como isolador térmico, diminuindo as perdas por evaporação do solo para a atmosfera, por outro lado, ela apresenta desvantagem, pois a água por ela interceptada e armazenada é perdida diretamente para a atmosfera, sem fazer parte do sistema solo-planta.

As equações lineares apresentadas na Figura 3 podem ser incorporadas aos modelos de balanço hídrico para contabilizar parte da água da chuva que não vai chegar ao reservatório do solo.

Na Figura 4, pode-se observar a velocidade da perda de umidade das diferentes quantidades de resíduos de milheto em função da ETP. Observa-se que, em todas as quantidades de palhada de milheto, houve perda quase total de umidade no final de um dia. Esse mesmo comportamento foi observado por Scopel et al. (1999) e por Findeling et al. (2003).

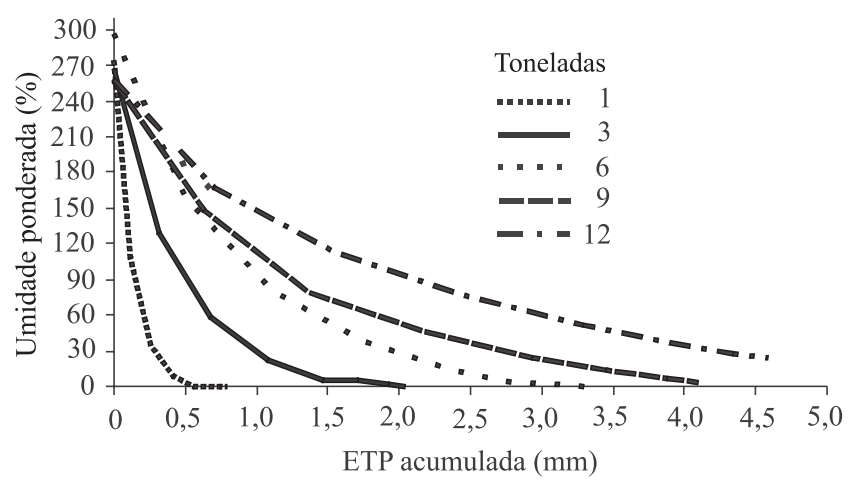

Figura 4. Velocidade de dessecação de diferentes quantidades $\left(t\right.$ ha $\left.{ }^{-1}\right)$ da palhada de milheto em relação à evapotranspiração potencial acumulada no dia (ETP acumulada). 
Verificaram-se duas fases distintas da evaporação da água da palhada do milheto (Figura 5). Na evaporação de 75 a $80 \%$ da umidade total da palhada, há proporcionalidade direta com a evapotranspiração potencial acumulada. No caso de $6 \mathrm{t} \mathrm{ha}^{-1}$, para $1,5 \mathrm{~mm}$ de evapotranspiração acumulada, observou-se proporcionalidade com a evaporação direta da palhada (1,5 mm), conforme a seta 1 da Figura 5. A partir desse valor, ela passa a ser menos intensa. A segunda seta destaca essa característica, pois, para $1,5 \mathrm{~mm}$ adicionais de ETP acumulada, a água evaporada da palhada foi aproximadamente $0,3 \mathrm{~mm}$. Isso também foi observado em todas as quantidades e tipos de palhada.

Pode-se afirmar que, na primeira etapa, a água armazenada pela palhada evapora facilmente, como num solo coberto com grama, com umidade na capacidade de campo; ou seja, nessa fase, a evaporação decorre da demanda evapotranspirativa. É nessa fase que acontece a evaporação de 75 a $80 \%$ da água total armazenada pela palhada. Na fase seguinte, a evaporação acontece em menor intensidade, quando comparada com a evapotranspiração acumulada. Da mesma forma que Findeling et al. (2003), pode-se afirmar que isso se deve ao fato de que, possivelmente, a partir desse momento, forças de resistência passam a atuar na transferência da água do interior para a superfície dos resíduos.

Os três tipos de palhada apresentaram comportamentos similares. Pode-se considerar que a evaporação da água das palhadas de milheto, milho e soja é sempre proporcional à ETP, ocasionada pela quantidade de energia recebida pelas palhadas, e pode ser expressa por um modelo exponencial que varia de acordo com a quantidade de palha.

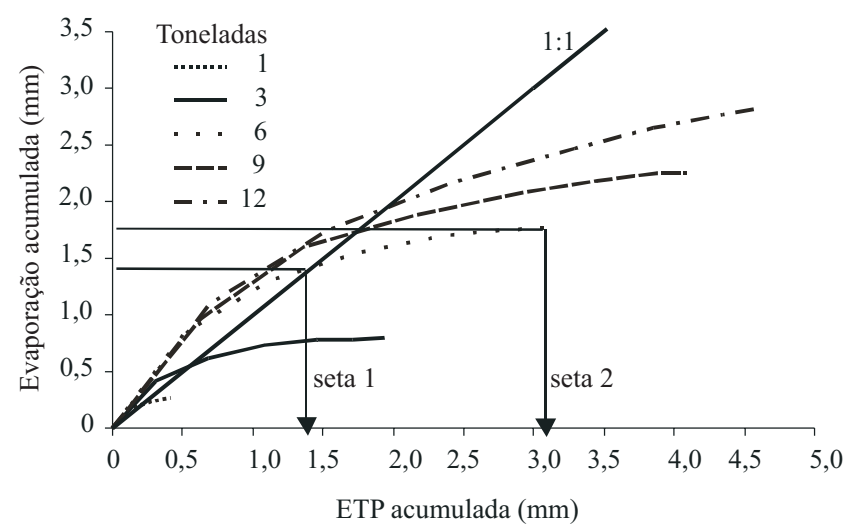

Figura 5. Evaporação acumulada de diferentes quantidades ( $\mathrm{t} \mathrm{ha} \mathrm{a}^{-1}$ ) da palhada do milheto em relação à quantidade de energia interceptada (ETP acumulada).
Na Tabela 1, apresentam-se as equações de estimativa da perda de umidade das palhadas de milho, milheto e soja. Esses modelos superestimam as perdas por evaporação direta por não considerar a segunda fase da evaporação dos resíduos. Considerou-se o solo coberto apenas pela palhada, sem contabilizar o efeito de uma cultura que pode interferir no balanço de energia. Apesar de o método superestimar a evaporação de água da palhada, é um importante subsídio na modelagem dos fluxos hídricos no sistema de plantio direto.

As medições do escoamento superficial nos sistemas de manejo convencional e de plantio direto permitiram evidenciar as diferenças entre as perdas de água da chuva ocasionadas pelos dois sistemas (Figura 6).

Assim como Gilley et al. (1986), constatou-se a eficiência dos resíduos no controle do escoamento superficial, pois, do total de $843,5 \mathrm{~mm}$ de água precipitada, durante o período experimental, apenas $45,5 \mathrm{~mm}$ foram perdidos pelo escoamento

Tabela 1. Coeficientes $\beta$ de ajustes da interceptação da radiação RFA e equações de estimativa da evaporação da água armazenada (EV, mm) nas palhadas de milho, milheto e soja, de acordo com a evapotranspiração potencial (ETP, mm) e da quantidade de palha $\left(\mathrm{Q}, \mathrm{t} \mathrm{ha}^{-1}\right)$.

\begin{tabular}{lccc}
\hline Tratamento & $\beta$ & Modelo & $\mathrm{R}^{2}$ \\
\hline Milho & 0,2403 & $\mathrm{EV}_{\text {palhada }}=\operatorname{ETP}\left(1-\mathrm{e}^{-0,2403 \mathrm{Q}}\right)$ & 0,87 \\
Milheto & 0,1585 & $\mathrm{EV}_{\text {palhada }}=\operatorname{ETP}\left(1-\mathrm{e}^{-0,1585 \mathrm{Q}}\right)$ & 0,95 \\
Soja & 0,1435 & $\mathrm{EV}_{\text {palhada }}=\operatorname{ETP}\left(1-\mathrm{e}^{-0,1435 \mathrm{Q}}\right)$ & 0,92 \\
\hline
\end{tabular}

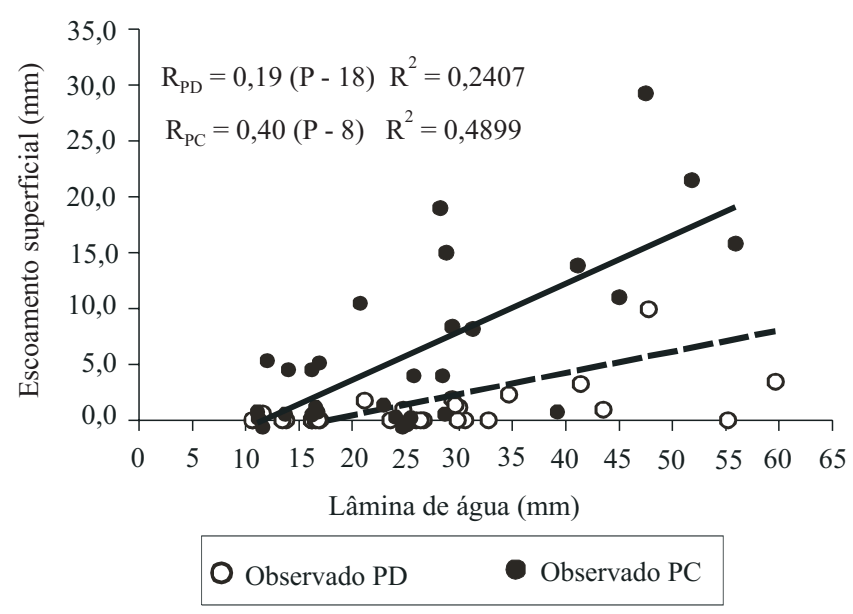

Figura 6. Coeficientes de determinação $\left(\mathrm{R}^{2}\right)$ e modelos lineares para estimativa do escoamento superficial nos sistemas de plantio direto $\left(\mathrm{R}_{\mathrm{PD}}\right.$, $\left.\mathrm{mm}\right)$ e convencional $\left(\mathrm{R}_{\mathrm{PC}}, \mathrm{mm}\right)$ em função das lâminas de água precipitada. 
superficial no sistema de plantio direto (5,4\% do total), enquanto no sistema convencional (solo descoberto e revolvido), as perdas foram de $222,5 \mathrm{~mm}$, o que corresponde a $26,4 \%$ do total da água precipitada.

Com base nos eventos de escoamento superficial ( $\mathrm{R}, \mathrm{mm}$ ), decorrente da chuva precipitada (P, mm), procedeu-se a uma análise estatística para ajustar os dados observados a uma regressão linear simples, da forma $\mathrm{R}=\alpha\left(\mathrm{P}-\mathrm{P}_{\text {lim }}\right)$, em que $\mathrm{P}_{\text {lim }}$ e $\alpha$ são os parâmetros empíricos do ajuste que significam, respectivamente, o valor limite da precipitação abaixo do qual não acontece escoamento superficial e a proporção de água escoada quando esse limite é ultrapassado.

Na Figura 6, os resultados indicam que, em geral, o escoamento superficial no sistema plantio direto só acontece quando a chuva ultrapassa $18 \mathrm{~mm}$, e que, a partir desse valor, $19 \%$ do total precipitado é escoado, enquanto no sistema convencional, perdas de água são verificadas quando a chuva passa de $8 \mathrm{~mm}$, sendo de $40 \%$ o porcentual escoado.

A modelagem do escoamento superficial é complexa, pois são muitas as variáveis que podem modificá-lo, tais como: umidade e tipo de solo, quantidade e qualidade da cobertura do solo, comprimento e declividade da rampa, intensidade da chuva, fase do ciclo da planta. Porém, mesmo que se utilize uma abordagem simples para quantificá-lo, tais como os modelos lineares, os resultados podem constituir subsídios importantes na contabilidade do balanço hídrico das culturas.

Verifica-se que os erros entre os valores observados e simulados pelos modelos lineares podem ser elevados em eventos pluviais isolados, mas, ao longo do ciclo, eles se compensam (Figura 6). Esses modelos empíricos ilustram a diferença de comportamento da água escoada nos tratamentos na escala do ciclo da cultura, porém, recomenda-se que sejam validados para condições diferentes das estudadas.

\section{Conclusões}

1. O comportamento da capacidade de armazenamento de água das palhadas de milho, milheto e soja pode ser expresso por um modelo linear.

2. A porcentagem de cobertura do solo e as quantidades de RFA e RIV que chegam ao solo podem ser estimadas por um modelo exponencial elaborado com base na quantidade dos resíduos de milho, milheto e soja.

3. Os resíduos remanescentes no solo, no sistema de plantio direto, diminuem o escoamento superficial que pode ser estimado por um modelo linear de acordo com a quantidade de chuva precipitada.
4. As equações quantificam impactos dos resíduos de milho, milheto e soja sobre os fluxos hídricos no sistema de plantio direto e podem ser incorporadas a modelos de simulação de crescimento e rendimento de plantas.

\section{Referências}

ARREOLA TOSTADO, J.M. Étude et modélisation de l'effet des paillis sur le bilan hydrique: le cas de semis direct sous paillis au Mexique. 1996. 82p. Dissertation (Diplôme d'Etudes Approfondies) - Université des Sciences et Techniques du Languedoc, Montpellier.

ARREOLA TOSTADO, J.M. Représentation spatialisée de l'effet du semis direct sur paillis de résidus sur la culture de maïs pluvial, dans l'etat de Jalisco, Mexique. 2000. 204p. Thèse (Doctorat) - Université de Bourgogne, Dijon.

DENARDIN, J.E.; KOCHHANN, R.A. Requisitos para implantação e a manutenção do sistema plantio direto. In: EMBRAPA. Centro Nacional de Pesquisa de Trigo (Passo Fundo, RS). Plantio direto no Brasil. Passo Fundo: Aldeia Norte, 1993. p.19-27.

DERPSCH, R. Agricultura sustentável. In: SATURNINO, H.M.; LANDERS, J.N. (Ed.). O meio ambiente e o plantio direto. Brasília: Embrapa SPI, 1977. p.29-48.

DERPSCH, R.; ROTH, C.H.; SIDIRAS, N.; KÖPKE, U. Controle da erosão no Paraná, Brasil: sistemas de cobertura do solo; plantio direto e preparo conservacionista do solo. Eschborn: GTZ; Londrina: Iapar, 1990. 268p.

FINDELING, A.; CHANZY, A.; DE LOUVIGNY, N. Modeling water and heat flows through a mulch allowing for radiative and long distance convective exchanges in the mulch. Water Resources Research, v.39, p.1-12, 2003.

GILLEY, J.E.; FINKNER, S.C.; SPOMER, R.G.; MIELKE, L.N. Runoff and erosion as affected by corn residue. II. Rill and interrill components. Transactions of the American Society of Agricultural Engineers, v.29, p.161-164, 1986.

IDSO, S.; REGINATO, R.; JACKSON, R.; KIMBALL, B.; NAKAYAMA, F. The three stages of drying of field soil. Soil Science Society of America Journal, v.38, p.831-836, 1974.

LAL, R. Mulching effects on runoff, soil erosion and crop response on alfisols in western Nigeria, Journal of Sustainable Agriculture, v.11, p.135-154, 1998.

NOVAK, M.; CHEN, W.; HARES, M. Simulating the radiation distribution within a barley straw mulch. Agricultural and Forest Meteorology, v.102, p.173-186, 2000.

RESCK, D.V.S. Agricultural intensification systems and their impact on soil and water quality in the Cerrados of Brazil. In: LAL, R. (Ed.). Soil quality and agricultural sustainability. Chelsea: Ann Arbor Press, 1998. p.288-300.

RITCHIE, J.T.; BURNETT, E. Dryland evaporative flux in a subhumid climate. II. Plante influences. Agronomy Journal, v.63, p.56-62, 1971. 
RUEDELL, J. A soja numa agricultura sustentável. In: SILVA, M.T.B. da (Ed.). A soja em rotação de culturas no plantio direto. Cruz Alta: Fundacep; Fecotrigo, 1998. p.1-34.

SALTON, J.C.; HERNANI, L.C.; FONTES, C.Z. Sistema plantio direto: o produtor pergunta, a Embrapa responde. Brasília: EmbrapaSPI; Dourados: Embrapa-CPAO, 1998. 248p. (Coleção 500 perguntas 500 respostas).

SATURNINO, H.M. Evolução do plantio direto e as perspectivas nos cerrados. Informe Agropecuário, v.22, p.5-12, 2001.
SAVABI, M.; STOTT, D. Plant residue impact on rainfall interception. Transactions of the American Society of Agricultural Engineers, v.37, p.1093-1098, 1994.

SCOPEL, E. Le semis direct avec paillis de résidus dans la région de V. Carranza au Mexique: intérêt de cette technicque pour améliorer l'alimentation hidrique du maïs pluvial en zones à pluviométrie irrèguliére. 1994. 334p. Thése (Doctorat) - Institut Nacional Agronomique Paris Grignon, Paris.

Recebido em 25 de abril de 2005 e aprovado em 9 de dezembro de 2005 